\title{
Influence of the Temperature Ramping Rate on the Performance of Vapor Transport Deposited SnS Thin- Film Solar Cells
}

Hyo Seok Lee, ${ }^{\dagger}$ Jae Yu Cho, ${ }^{\dagger}$ Raju Nandi, ${ }^{\dagger}$ Pravin S. Pawar, ${ }^{\dagger}$ KrishnaRao Eswar Neerugatti, ${ }^{\dagger}$ Cuc Thi Kim Mai, ${ }^{\ddagger, \S}$ Doh-Kwon Lee, ${ }^{\ddagger, \S}$ and Jaeyeong Heo ${ }^{*,+}$

${ }^{\dagger}$ Department of Materials Science and Engineering, and Optoelectronics Convergence Research Center, Chonnam National University, Gwangju 61186, Republic of Korea ${ }^{\ddagger}$ Photo-electronic Hybrids Research Center, Korea Institute of Science and Technology (KIST), Seoul 02792, Republic of Korea

${ }^{\S}$ Division of Nano and Information Technology, KIST School Korea University of Science and Technology, Seoul 02792, Republic of Korea

*Corresponding Author:

E-mail address: jheo@jnu.ac.kr 


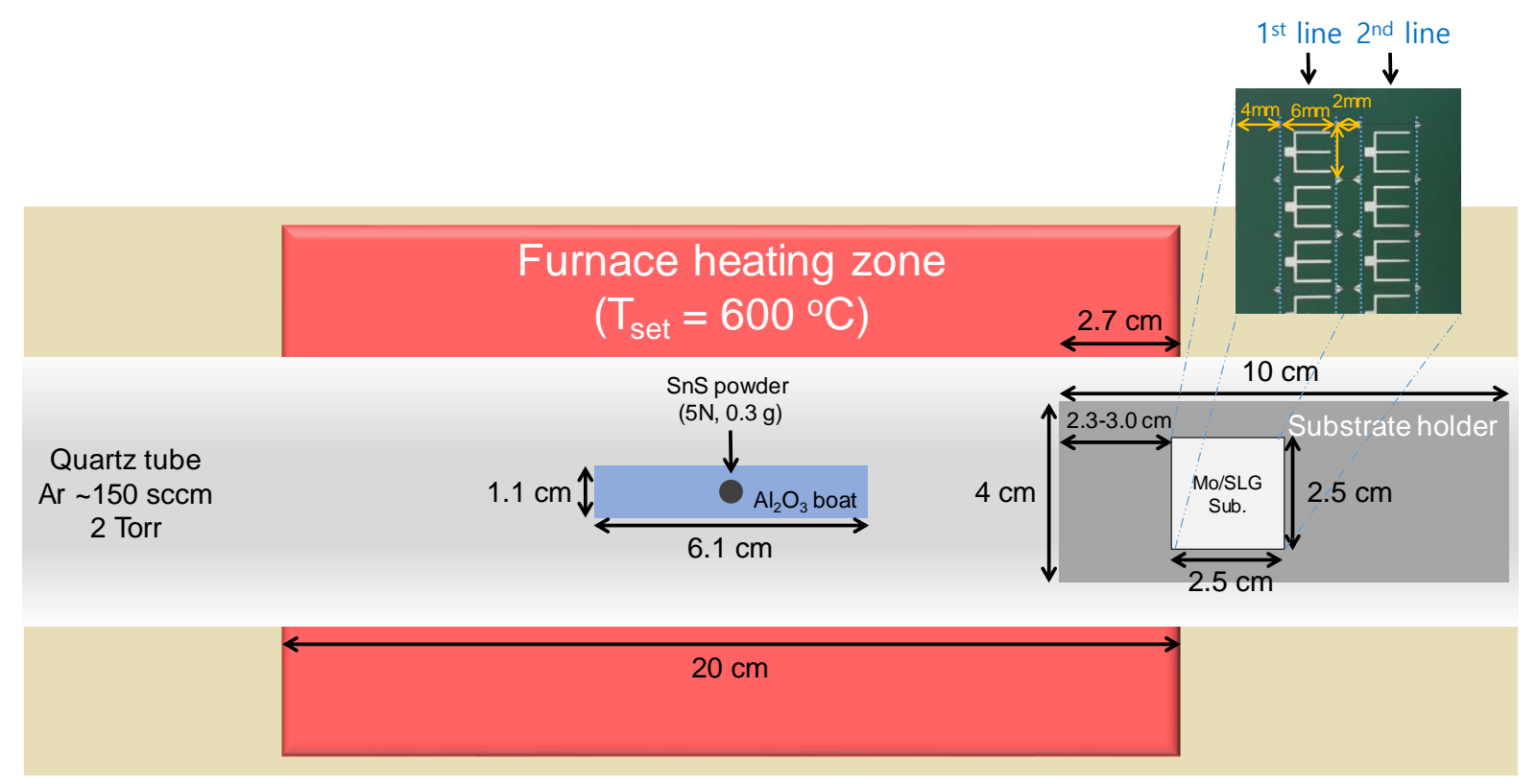

Figure S1. Schematic for the VTD system with detailed information on the location of the substrate. Three cells were fabricated for the $1^{\text {st }}$ and $2^{\text {nd }}$ lines with a total of 6 cells.
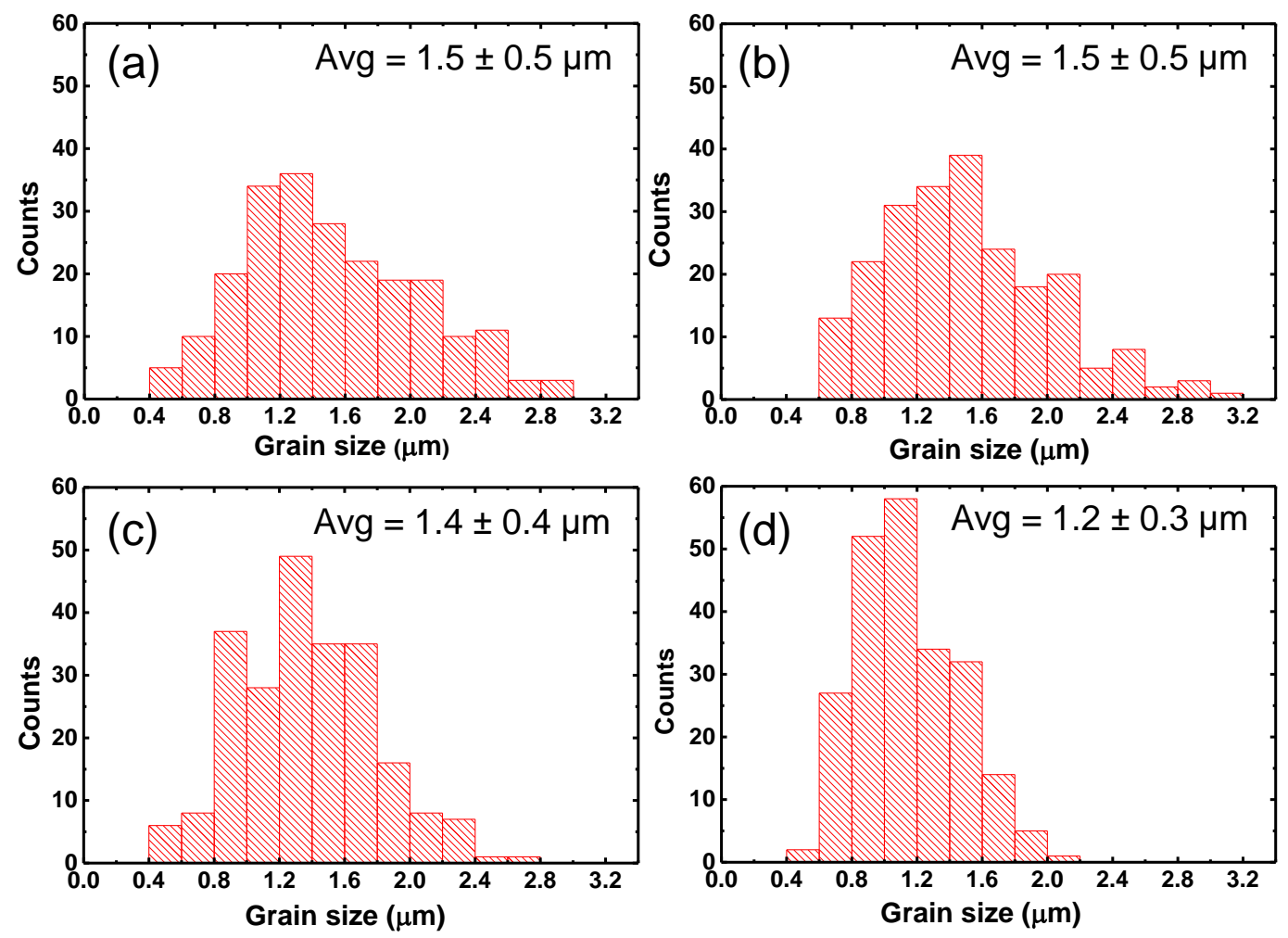

Figure S2. Histogram of lateral grain size distribution of VTD-grown SnS-absorber layers deposited at various temperature ramping rates (a) $5{ }^{\circ} \mathrm{C} \mathrm{min}^{-1}$, (b) $6.7^{\circ} \mathrm{C} \mathrm{min}{ }^{-1}$, (c) $10{ }^{\circ} \mathrm{C}$ min $^{-}$ 1 , and (d) $20{ }^{\circ} \mathrm{C} \mathrm{min}^{-1}$. 


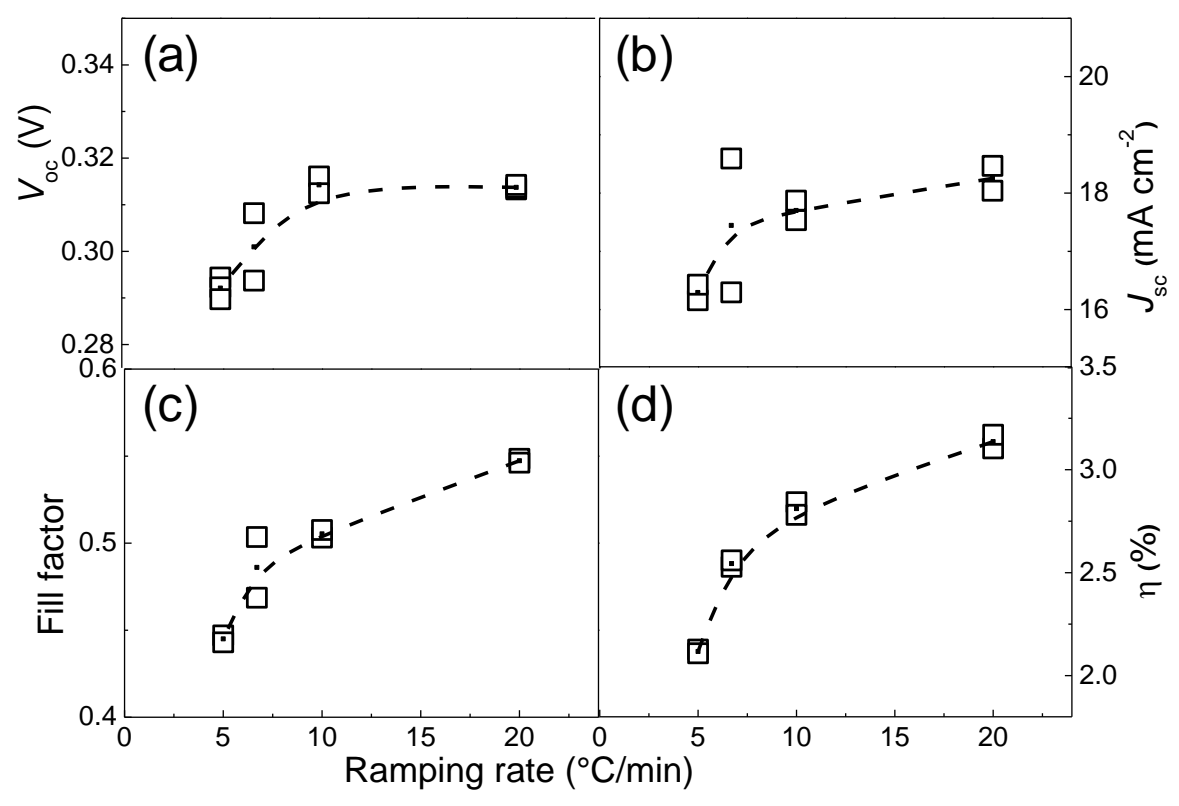

Figure S3. Solar cell performance of the three cells closer to the heating line region (see three cells in the " 1 st line" in Figure S1): (a) $V_{\text {oc }}$, (b) $J_{\text {sc }}$, (c) fill factor, and (d) $\eta$. Improvement in the fill factor mainly leads to an increase in $\eta$.

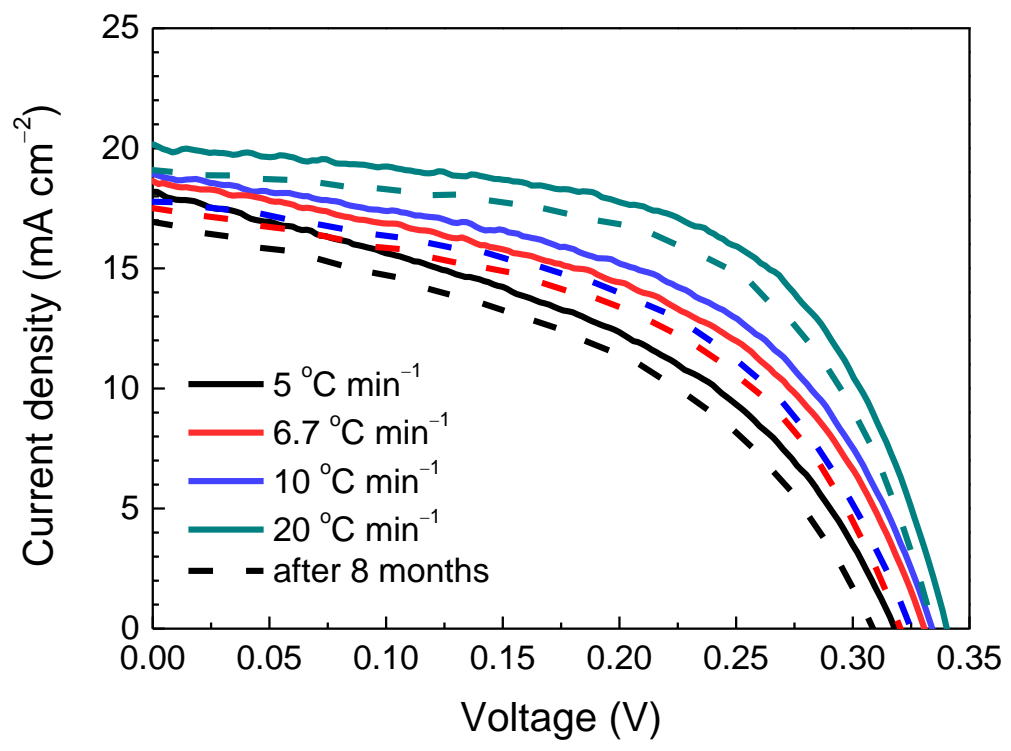

Figure S4. $J$ - $V$ characteristics of the champion cells of as-prepared SnS-TFSCs and 8 months after of device fabrication. 


\begin{tabular}{|c|c|c|c|}
\hline $\begin{array}{c}\text { Temperature } \\
\text { ramping rate } \\
\left({ }^{\circ} \mathrm{C} \mathrm{\text {min } ^ { - 1 } )}\right.\end{array}$ & $\begin{array}{c}\text { Initial } \\
\text { efficiency }(\%)\end{array}$ & $\begin{array}{c}\text { Efficiency after } \\
8 \text { months }(\%)\end{array}$ & $\begin{array}{c}\text { Efficiency } \\
\text { retention }(\%)\end{array}$ \\
\hline 5 & 2.49 & 2.30 & 92.4 \\
\hline 6.7 & 3.02 & 2.76 & 91.4 \\
\hline 10 & 3.24 & 2.90 & 89.5 \\
\hline 20 & 3.98 & 3.72 & 93.5 \\
\hline
\end{tabular}

Table S1. Efficiency retention of the champion cells after 8 months of device fabrication.

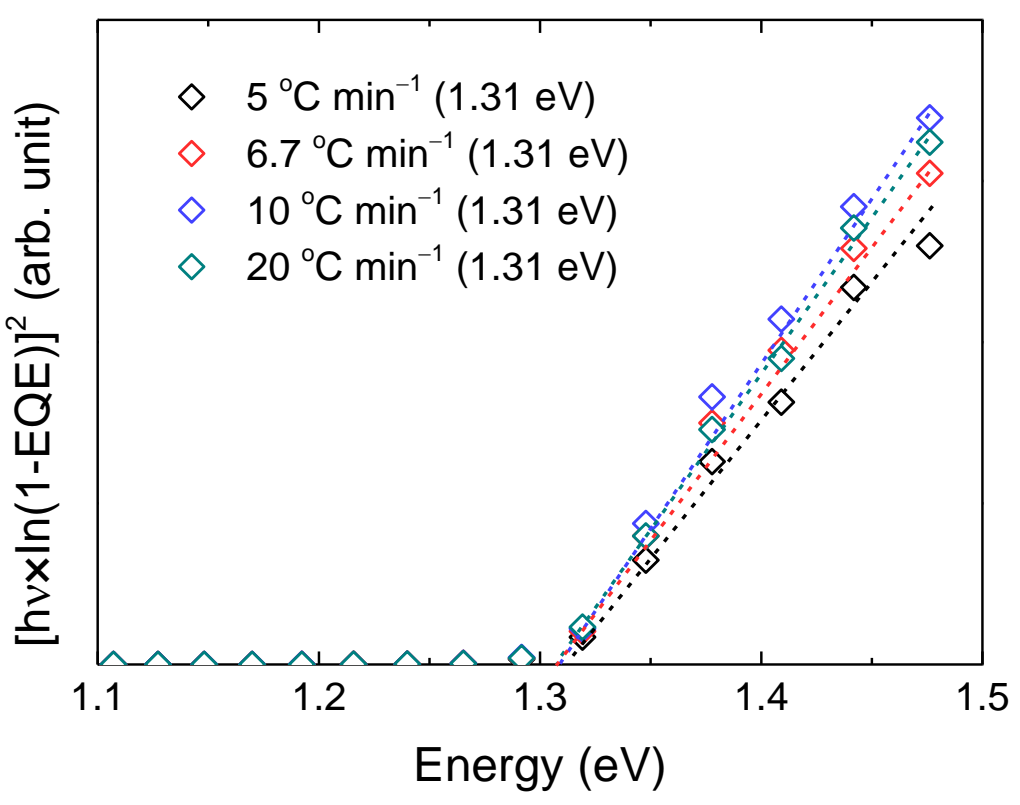

Figure S5. Band gap extraction from the EQE data for the SnS absorbers. 
(a)

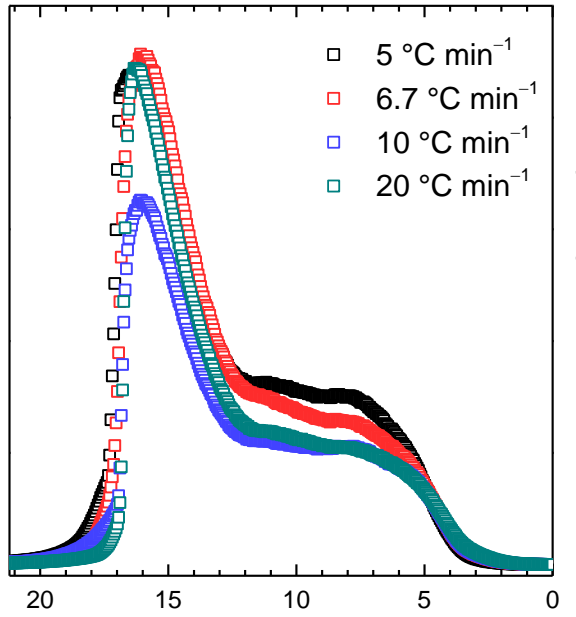

(b)

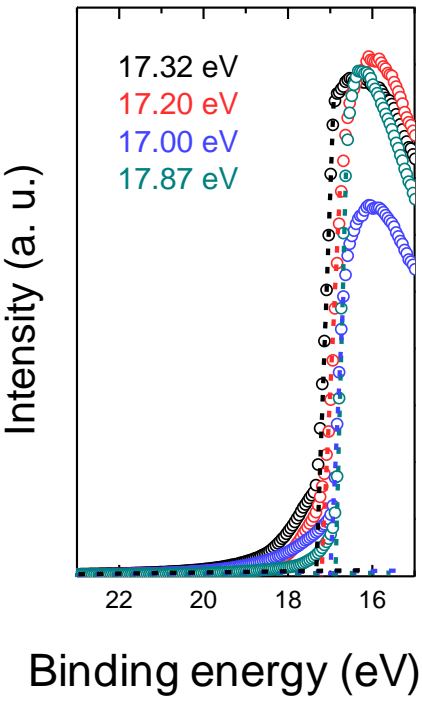

(c)

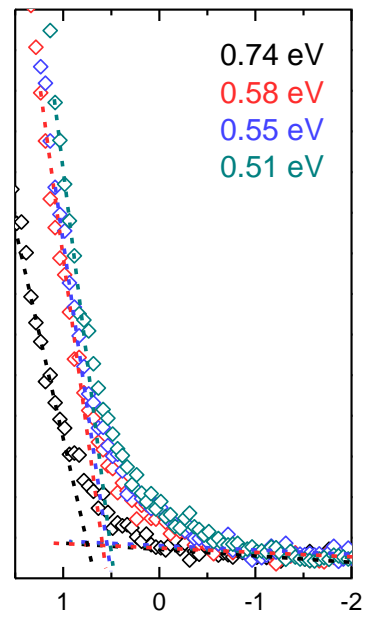

Figure S6. (a) UPS spectrum of various $\mathrm{SnS}$ absorbers grown on Mo substrates. (b) The work function was determined from the secondary electron cutoff (SEC) using the equation WF = $21.22 \mathrm{eV}-$ SEC. (c) The low binding energy onset in the figure was used for the calculation of the difference between the Fermi level and valence band maximum.

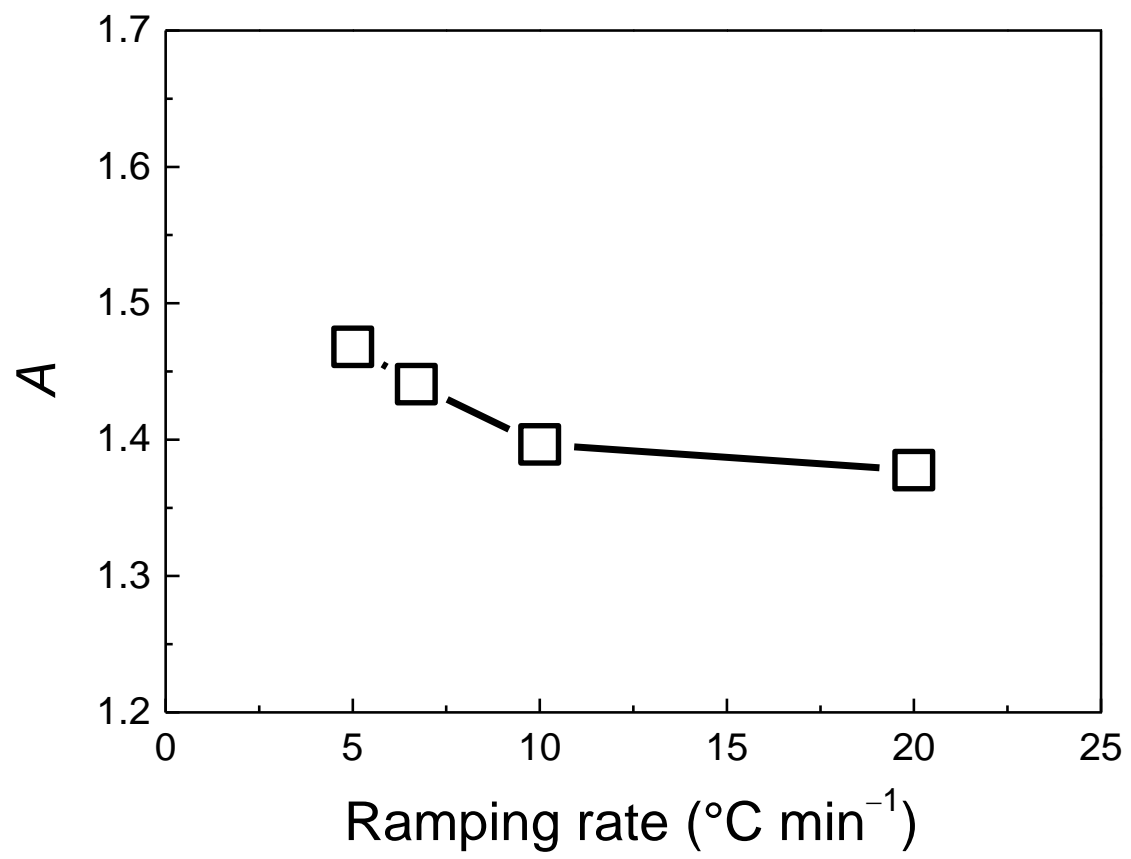

Figure S7. Ideality factor of the SnS/CdS TFSCs as a function of temperature ramping rate. 